\title{
Social Network Sites, Fear of Missing Out, and Psychosocial Correlates
}

\author{
Ben Classen, Jay K. Wood, \& Patsi Davies \\ Auckland University of Technology, Auckland, New Zealand
}

\begin{abstract}
The use of Social Network Sites (SNSS) has grown to become a ubiquitous aspect of daily life in developed countries throughout the world. This rise of social media has resulted in increased public concern regarding the way in which individuals engage with SNSS, and the consequences of frequent SNS use. The Fear of Missing Out (FoMO) is an example of a social psychological phenomenon which has recently received attention as a significant factor associated with experiences of SNS engagement. The following study sought to contribute to developing understandings of SNS use and FoMO. This was achieved by assessing the extent to which FoMO mediated the relationships between SNS engagement and four other psychosocial factors (psychological need satisfaction, social capital, public self-consciousness, and public self-monitoring). Quantitative data were collected from a student volunteer sample of 218 New Zealand SNS users and analysed using a series of regression analyses. Relationships between each of the assessed psychosocial variables and rates of SNS engagement were found to be mediated by FoMO. The findings of this study support the view that FoMO plays an important role in understanding the range of complex and interrelated psychosocial factors relating to rates of SNS engagement.
\end{abstract}

Keywords: SNS; FoMO; social capital; psychological need satisfaction; public self-monitoring; public selfconsciousness

\section{Introduction}

The widespread use of SNSs has had a profound impact on developed societies throughout the world. By speeding up the rate at which information travels within and across social networks, SNSs are effecting significant changes to communication norms (Waterloo et al., 2017), rates of cultural development (Milner, 2016), human neurophysiology (He et al., 2017), and patterns of social behaviour (David \& Roberts, 2017). A key factor contributing to these changes to daily life is the rate at which individuals are using SNSs. With frequency and intensity of engagement with SNSs being consistently associated with the health and wellbeing of users (Frost \& Rickwood, 2017; Sherlock \& Wagstaff, 2018), high rates of SNS engagement (Qutteina et al., 2019; Shimoga et al., 2019), and the closely related phenomenon of problematic or pathological use of SNS (Hawi \& Samaha, 2017; Holmgren \& Coyne, 2017; Oberst et al., 2017; Xue et al., 2018), are increasingly being considered as prevalent public health concerns throughout the modern world. There is therefore considerable practical interest in understanding how and why people are engaging with SNS technologies. One area within this field which has received a good deal of attention is the way in which psychosocial factors such as FoMO (Przybylski et al., 2013), social capital (Ellison et al., 2007) and depression (Jelenchick et al., 2013) interrelate with patterns of SNS use. By better understanding how psychological and social aspects of user's lives might predict patterns of SNS use, we are arguably better equipped to minimise the potential harm of problematic SNS use. The following study therefore sought to contribute to this growing body of literature by examining the relationships between a selection of psychosocial variables and rates of engagement with SNS use. In light of recent concern in the field of 
social psychology regarding replicability of findings (Finkel \& Baumeister, 2019), this study sought to partially replicate, and expand upon, a key study within the field of online social psychology.

This involved quantitatively assessing potential correlations between four psychosocial variables, along with the extent to which these correlations were mediated by FoMO. The four psychosocial variables examined were each deemed to be potentially correlated with both rates of SNS engagement, and experiences of FoMO. Based on previous similar research (Przybylski et al., 2013) psychological need satisfaction was expected to impact user's motivations to use SNSs, with this relationship being at least partly mediated by FoMO. As such, the present study sought to re-affirm established relationships between SNS use, Psychological Need Satisfaction, and FoMO. These findings were then extended by investigating three additional and potentially related psychosocial factors. Public self-consciousness was predicted to relate to SNS use and FoMO, as individuals with greater awareness of themselves in a public context were expected to feel a greater obligation to engage with online media sites based around relatively public personal profiles. Similarly, public self-monitoring was included as higher public selfmonitors were expected to be more inclined to take advantage of SNS features as a means of managing and maintaining their online public identities. Lastly, online social capital was predicted to impact the perceived incentive for users to engage with SNSs, along with susceptibility to experiencing FoMO.

\section{FoM0}

One example of how SNS use has come to impact psychological and social experiences can be seen in the rise of a new type of social anxiety commonly referred to as the Fear of Missing Out (FoMO). This term has become something of a pop culture buzzword in recent years (Barker, 2016; BBC, 2017), and has been succinctly defined by Przybylski et al. (2013) as "...a pervasive apprehension that others might be having rewarding experiences from which one is absent" (p.1841). The term first began to appear in public discourse earlier this decade (Fake, 2011). However, it has been suggested that FoMO as a social phenomenon has been around for as long as there have been means for keeping up to date with what people are doing elsewhere, such as letters, newspapers, and email (Wortham, 2011). Arguably this awareness of what one might be missing out on has never been more apparent than in the digital age. With the phenomenal saturation of SNS use throughout the developed world, users are constantly bombarded with social information, as well as opportunities to engage with their social networks. This has resulted in FoMO being consistently identified as a factor associated with problematic patterns of SNS engagement (Appel et al., 2019; Dhir et al., 2018; Oberst et al., 2017; Robson, 2018). A number of studies have also demonstrated correlations between FoMO and an array of psychological factors including psychological need satisfaction (Przybylski et al., 2013), depression (Oberst et al., 2017), anxiety (Wolniewicz et al., 2019), and general negative affect (Wolniewicz et al., 2018). FoMO has also been found to mediate the relationships between SNS use and a range of psychological and psychosocial factors including loneliness and depression (Reer et al., 2019), anxiety (Elhai et al., 2020), sensation seeking (Wang et al., 2019), and subjective well-being (Chai et al., 2019). As understandings of exactly how and why individuals engage with SNSs continue to develop, so too do our understandings of the nature of FoMO and how these two aspects of life in the digital age are related.

\section{Psychological Need Satisfaction}

Psychological need satisfaction is one example of a psychosocial factor which has been shown to be associated with patterns of SNS engagement (Masur et al., 2014; Przybylski et al., 2013; Sheldon et al., 2011). Psychological need satisfaction refers to the extent to which an individual feels that a range of fundamental psychological needs (autonomy, competence, and relatedness) are being satisfied on a day-to-day basis (Deci \& Ryan, 1985). Psychological need satisfaction therefore relates to SNS engagement as each of these basic needs are ones which have the potential to be satisfied in online virtual environments (Przybylski et al., 2010). This implies that deficits in meeting fundamental psychological needs have the potential to impact motivations for and regulation of online behaviours. Furthermore, Przybylski et al. (2013) found that deficits in psychological need satisfaction correlated with levels of SNS engagement, and that FoMO partially mediated this correlation. By including psychological need satisfaction, FoMO and SNS engagement as variables in the present study, we sought to reaffirm Przybylski et al.'s original findings in an Australasian context. 


\section{Social Capital}

Social capital as a psychosocial factor relates to an individual's perceived benefit from social networks and relationships (Putnam, 2000). Putnam (2000) outlined two types of social capital - bonding and bridging - each of which refer to different aspects of an individual's social networks. Bonding social capital refers to social ties with people who are emotionally close and supportive, such as family and close friends, while bridging social capital refers to comparatively 'weak' ties, which are maintained over time and provide a source of potential future social benefit (Ellison et al., 2007). Both of these aspects of overall social capital were examined in the present study. The relationship between these forms of social capital and internet use has been established in existing literature on the topic, a notable example of which is Williams' (2006) development of a series of scales for assessing bridging and bonding social capital in online environments. Since this distinction of online social capital, correlations have been established between SNS use and the formation and maintenance of social capital online (Ellison et al., 2007), as well as between certain types of online behaviours whilst using SNS and the development of social capital (Steinfield et al., 2009). In one of the most recent studies of social capital and SNS use, Yoo and Jeong (2017) found that participants with both high and low rates of social capital used SNS just as frequently over a one-year period, challenging assumptions that greater or lower social capital might be used to predict rates of SNS engagement.

Similar to the existing links between social capital and SNS use, there may be reason to suspect an association between social capital and experiences of FoMO. It seems reasonable to presume that the increased social connectivity experienced by individuals with greater social capital may open up more opportunities for feelings of FoMO. More expansive social networks may result in an individual having a greater awareness of social activities they are missing out on, thus resulting in a positive correlation between perceived social capital and experiences of FoMO. Conversely, an increase in social capital could also result in a decreased likelihood of experiencing FoMO. With a more established social network an SNS user may be less prone to experiences of FoMO, as they could conceivably be less likely to feel insecure about missing out on social events. Although previous studies have established positive correlations between FoMO and social factors such as a need for popularity (Beyens et al., 2016), at the time of conducting the present study we found an absence of empirical evidence showing a relationship between FoMO and social capital as a stand-alone social construct.

\section{Public Self-Consciousness}

Public self-consciousness is a psychosocial factor which was proposed by Fenigstein et al. (1975) as an integral aspect of general self-consciousness. The term public self-consciousness refers to the extent to which an individual is aware of themselves as an object of social attention in a social context. The broader concept of selfconsciousness has been established within the literature as being associated with a range of patterns of behaviour (Baumeister, 1984; Lundh \& Öst, 2001) and psychological wellbeing (Lowery et al., 2005; Wiederman, 2000). Issues regarding the psychological implications of high public self-consciousness have become particularly salient with the rise of SNS platforms, many of which are structured around portraying one's identity in a public setting (Seidman, 2013). Public self-consciousness has been found to be directly associated with the way people engage with SNS platforms (Lee et al., 2012), especially with regards to the way individuals construct and present themselves online (Seidman, 2013). Studies such as those by Shim et al. (2008), Lee et al. (2012), and Chua and Chang (2016) indicate that the extent to which users are conscious of themselves in relation to their social environment influences behaviours whilst using SNSs. However, although such studies demonstrate clear relationships between public self-consciousness and frequency of behaviours when online, empirical evidence of an association between this psychosocial variable and overall rates of engagement with SNSs are harder to find. Such a relationship is plausible, as by engaging with SNSs individuals are made acutely aware of their social networks, and by extension, their positioning within these environments. People with high rates of public selfconsciousness may be attracted to using SNSs more frequently due to the utility of SNSs as a means of curating public identities.

Additionally, public self-consciousness was also predicted to be correlated with experiences of FoMO. The rationale behind this hypothesis was that individuals who are more conscious of themselves in a public context may have a heightened awareness of missed social opportunities and the consequences of these events in relation to their less socially self-conscious counterparts. Public self-consciousness was therefore analysed in the present study as a psychosocial factor with the potential to be correlated with both SNS engagement and FoMO. 


\section{Public Self-Monitoring}

Whereas public self-consciousness refers to an individual's awareness of themselves as an object of social attention, public self-monitoring refers to the extent to which an individual monitors and regulates their own behaviour in a public social setting (Snyder, 1974). High self-monitors engage in frequent self-observation and adapt their behaviours to suit their social environment, whereas low self-monitors spend less time managing their public identity and are more likely to exhibit behaviours which they feel are consistent with their true selves (Brown, 1998). This psychosocial factor was perceived to be relevant to developing understandings of problematic SNS use based on the typical nature of SNSs. A core aspect of SNS platforms is an online public profile/identity, the presentation of which may be closely monitored and managed by the user (Livingstone, 2008). This ability to customise and personalise online identities provides high self-monitoring individuals with the opportunity to effectively manage their social behaviours and appearances, a fact which was hypothesised to be reflected in any potential correlation between perceived public self-monitoring and SNS use. Furthermore, it was expected that SNS users who are more prone to public self-monitoring may be more susceptible to experiencing FoMO in relation to their SNS use. This is due to the opportunities for observing and reacting to social information afforded by SNS. High public self-monitors may be more prone to fearing they will miss out on opportunities to manage their online identities and maintain awareness of happenings within their social networks.

\section{Method}

\section{Pilot Study}

Data was collected via online questionnaire/survey platform surveymonkey.com. Prior to the primary data collection, a small pilot study was conducted in which a group of six volunteers worked through an initial incarnation of the online questionnaire and provided feedback on the clarity of the questions, time taken to completion, and general feedback on their experience completing the questionnaire. This feedback allowed for the correction of minor grammatical inconsistencies in the questions and provided useful information on time taken to completion, an estimate of which was provided to potential participants during recruitment for the primary study.

\section{Primary Study}

We collected data from a sample of 218 New Zealand SNS users. Prior to participating, all participants were assured of the ethical considerations taken into account whilst designing the study and were required to provide informed consent for their anonymised data to be used in the study. The final questionnaire included both a quantitative and qualitative component, however the qualitative aspect of this study is beyond the scope of this article. All participants were volunteers and a random small prize draw was utilised to assist in reaching the sample size. Participants were recruited via in class announcements and the distribution of posters and fliers throughout university campuses, resulting in $96.8 \%$ of participants being enrolled University students. This non-random sample of students was chosen as the focus of our investigation into psychosocial correlates of SNS use based on typically high rates of SNS engagement within student populations both internationally (Spraggins, 2009; Tang \& Koh, 2017), and in New Zealand (Dabner, 2012). A sample size of at least 200 was chosen based on the assumption that this sample would be large enough to detect at least small-to-medium mediation effects using the percentile bootstrap method (Fritz \& MacKinnon, 2007). Posters and fliers contained a URL link to the online survey and a QR code which when scanned using a smartphone app, linked the potential participant directly to the online questionnaire. Potential participants were expected to be at least somewhat familiar with QR code/barcode scanning smartphone applications which are widely available on mobile app stores and are increasingly used in contemporary consumer communication and marketing strategies (Cata et al., 2013; Dou \& Li, 2008). This recruitment strategy proved highly effective, with $98 \%$ of respondents using a QR code to access the online questionnaire.

The quantitative component of the online questionnaire involved six different survey tools, each of which has been previously established and independently validated within the literature. The first tools were the social media engagement questionnaire (SMEQ), and the FoMO scale (FoMOs), both of which were designed, validated and 
originally used by Przybylski et al. (2013). Each of the four remaining tools were used to assess an individual psychosocial variable. In order to ensure the validity of the replication aspect of this study, those tools which were used and designed in Przybylski et al.'s (2013) study (SMEQ, FoMOs, and the Psychological Need Satisfaction Scale (PNSS)) were implemented in a way which was as faithful to the original study as possible. Each of these measures were originally validated by Przybylski et al. (2013), and are still actively being used within contemporary social psychological research (SMEQ - Reer et al., 2019; FoMOs - Wang et al., 2019; PNSS - Rahmadani et al., 2019). The remaining three measures, which constitute the novel component of this study, were chosen based on review of best methodological practice within the field. The various quantitative survey tools and other general items were presented to participants in the following order.

\section{General Questions}

Participants were asked to confirm that they were users of SNS and indicate which SNS platforms they currently have a profile on. These demographic data were collected in order to provide a greater depth of understanding regarding the particular SNS platforms being frequented by users.

\section{Social Media Engagement Questionnaire (SMEQ)}

This tool was originally developed by Przybylski et al. (2013) and is used to assess participants' perceptions of the extent of their social media engagement. By asking participants questions relating to how frequently they use SNS at particular times of the day (i.e. after waking, while eating lunch), the social media engagement questionnaire (SMEQ) provides insight into rates of engagement with SNS. By measuring SNS use in relation to specific daily activities, participants are provided with a useful cognitive cue when recalling their behaviour, a feature of this tool which ideally improved the reliability of the self-report data (Tourangeau, 2018). Participants were asked to consider their social media use over the past week whilst responding to five statements such as "I used social media while eating my breakfast" and "I used social media within 15 minutes of going to sleep" using an 8-point scale. This scale ranged from 1 (not one day last week) to 8 (every day last week). Scores for each participant were summed to create a single social media engagement score. Possible scores ranged from 5 to 40 , with a higher score indicating more frequent SNS engagement (Original study $a=.82$, present study $\alpha=.80$ ).

\section{Fear of Missing Out Scale (FoMOs)}

Przybylski et al.'s (2013) FoMO scale (FoMOs), was developed as a means of accurately assessing experiences of FoMO. The scale was developed with a large sample of adult participants, and involved conducting a range of validity analyses on a pool of 32 potential items. The result was a 10-item scale which has become a widely used measure across the field (Alt, 2015; Chotpitayasunondh \& Douglas, 2016; Hetz et al., 2015; Oberst et al., 2017). The scale has since been translated into multiple different languages and been independently validated in crosscultural contexts (Al-Menayes, 2016; Gökler et al., 2016; Perrone, 2016). FoMOs was used in the present study to assess the extent to which participants experienced FoMO. It consisted of 10 items including "I fear others have more rewarding experiences than me", and "I get worried when I find out my friends are having fun without me". Participants responded to these 10 items on a 5-point scale ranging from 1 (not at all true of me) to 5 (extremely true of me). Scores for each scale were averaged to create a single score indicative of the participant's propensity to experience FoMO. Possible scores ranged from 1 to 5 , with higher scores indicating that participants were more likely to experience FoMO (Original study $a=.87$, present study $\alpha=.80$ ).

\section{Internet Social Capital Scale (ISCS)}

Since the establishment of social capital as an indicator of individual and societal wellbeing, a range of survey tools have been developed which assess levels of social capital in a range of real world contexts (Chen et al., 2009; Onyx \& Bullen, 2000). However, it was Williams (2006) who developed a social capital tool which specifically relates to internet social capital. The Internet Social Capital Scales (ISCS) assess levels of bridging and bonding social capital both on and off the internet as a means of comparing the differences between online and offline social contexts. This tool was rigorously validated by Williams and is arguably the most reliable measure of internet social capital to date. Since its conception, it has been effectively used to assess social capital in a wide range of studies which examine the relationship between online social capital and SNS use (Ellison et al., 2011; Ellison et al., 2014; 
Steinfield et al., 2009; Yoo \& Jeong, 2017). This scale was therefore selected to measure internet social capital in the present study. The 20-item scale consisted of two 10 item subscales which assessed a participant's perceived bridging and bonding social capital, respectively. Sample items included "Interacting with people online makes me want to try new things", and "Interacting with people online gives me new people to talk to". Participants responded to both subscales using a 5-point scale ranging from 1 (Not at all true of $m e$ ) to 5 (Extremely true of me). Scores were then averaged to create an overall bridging and bonding score for each participant. Possible scores ranged from 1 to 5 with higher scores indicating a higher degree of social capital (Original study $a=.90$, present study $a=.90)$.

\section{Public Self-Monitoring Scale (SMS-R)}

Snyder (1974) originally theorised the concept of public self-monitoring and developed the self-monitoring scale (SMS) as a means of measuring this psychosocial variable. In response to criticism of the validity of the selfmonitoring construct, and the utility of the SMS as a reliable measure (Briggs et al., 1980; Lennox \& Wolfe, 1984), Snyder and Gangestad (1986) conducted a rigorous reanalysis of the original SMS and published a revised version of the scale (SMS-R). This revised self-monitoring scale is a shortened version of the original measure and continues to inform contemporary research into self-monitoring behaviours (Wilmot et al., 2016). Based on this background, the SMS-R was used in the present study to assess the extent to which participants are aware of and regulate their behaviour and self-presentation in a social context. Participants responded to the 18-item scale using true or false answers. Sample items included "I find it hard to imitate the behaviour of other people", and "I guess I put on a show to impress or entertain others". Each question was initially coded by the researchers as either true or false, and higher self-monitoring participants were expected to answer in the coded direction more often. Possible scores therefore ranged from 0 to 18 , and indicated the extent to which participants engaged in public self-monitoring behaviours (Original study $a>.70$, present study $a=.64$ ).

\section{Public Self-Consciousness Scale (PSCS)}

Fenigstein et al. (1975) developed a tool for assessing individual differences in self-consciousness. This measure consists of three sub-scales for assessing each of the three identified dimensions of self-consciousness. The public self-consciousness component of this tool is a seven-item scale which has since been effectively implemented in a range of studies examining public self-consciousness (Miller \& Cox, 1982; Green et al., 2017). A slightly simplified version of Fenigstein et al.'s (1975) public self-consciousness subscale was therefore used in the present study to measure experiences of public self-consciousness. This simplification was done in attempt to reduce the cognitive burden on participants completing an already extensive questionnaire. The original version of this scale saw participants answering seven items using a 7-point Likert scale. For the purposes of this study, the tool was simplified and had participants answer the same seven items using true or false answers. True answers were given a score of 1 and false answers were given a score of 0 . Sample items included statements such as "I'm concerned about my style of doing things", and "I'm self-conscious about the way I look". The scores for each participant were summed to give an overall public self-consciousness score. Possible scores therefore ranged from 1 to 7 , with higher scores indicating higher public self-consciousness. The modified version of this scale maintained a good degree of internal reliability in comparison with the original version (Original study $a>.70$, present study $a=.70$ ).

\section{Psychological Need Satisfaction Scale (PNSS)}

In a study on individual attachment and well-being, La Guardia et al. (2000) developed and validated a brief nineitem scale for assessing psychological need satisfaction. By utilising questions which directly relate to participants' general feelings of autonomy (e.g., "I feel free to be who I am"), competence (e.g. "I feel like a competent person"), and relatedness (e.g. "I feel loved and cared about"), the psychological need satisfaction scale (PNSS) is one which is applicable to a range of research areas. An example of the utility of this measure is shown by Przybylski et al. (2013), who effectively used the psychological need satisfaction scale (PNSS) to demonstrate the correlation between psychological need satisfaction and rates of SNS use. Based on this, a slightly modified version of the PNS scale (La Guardia et al., 2000) was used in the present study to assess the extent to which participants had a range of their basic psychological needs met on a daily basis. The scale consisted of nine items such as "In my everyday life, I feel free to be who I am", and "I often feel like a competent person". In the original application of this tool, participants responded to these nine items using a 7-point scale. For the purposes of this study, potential 
participant responses for each of the same nine items were simplified down to either true or false answers. True answers were given a score of 1 , and false answers were given a score of 0 . As with the original version of the tool, items 4, 6 and 9 were reverse scored. The overall scores were then averaged to give each participant a PNS score ranging from 0 to 1, with a higher score indicating a greater level of PNS. This modified version of the PNSS maintained a degree of internal reliability which was consistent with the original version of the tool (Original study $a=.83$, present study $a=.80$ ).

\section{Demographic Questions}

Finally, participants were asked to provide some basic demographic information including their year of birth, gender, and ethnicity. These questions were included to provide more data on the demographic make-up of the sample. After completing these final questions, participants were presented with the opportunity to enter the random prize pool by providing an email address.

\section{Results}

\section{Preliminary Analysis}

With 218 participants and more than 80 quantitative questions, the amount of data collected in this study was consistent with previous research in this field (Przybylski et al., 2013). All quantitative data was organised and analysed using SPSS statistics software. The mean scores and standard deviations for each of the key variables are displayed in Table 1. This software was also used to create an overview of the associations among the variables (Table 2). SNS engagement was found to be significantly correlated with FoMO and social capital, and FoMO was found to be significantly correlated with all key variables in the study. Bridging social capital also proved to be an important factor and was significantly correlated with all other primary variables aside from psychological need satisfaction. Of the 218 total participants, 214 participants provided complete responses to the questionnaire's demographic questions. Initial analyses were conducted to identify any systemic trends in responses within the demographic make-up of the participants. The demographic variables and the analyses used to assess them are outlined below.

Table 1. Mean Scores and Standard Deviations for Primary Variables.

\begin{tabular}{lccc}
\hline & Females $M(S D)$ & Males $M(S D)$ & Total $M(S D)$ \\
\hline SMEQ & $27.57(7.9)$ & $26.60(9.2)$ & $27.42(8.2)$ \\
FoMOs & $2.30(0.6)$ & $2.17(0.6)$ & $2.27(0.6)$ \\
SMS-R & $8.62(3.0)$ & $10.03(3.6)$ & $8.96(3.2)$ \\
PNSS & $0.76(0.2)$ & $0.71(0.2)$ & $0.74(0.2)$ \\
PSCS & $4.90(1.9)$ & $4.83(1.5)$ & $4.90(1.8)$ \\
SC Bonding & $2.23(0.5)$ & $2.46(0.6)$ & $2.28(0.5)$ \\
SC Bridging & $2.76(0.8)$ & $2.95(0.8)$ & $2.81(0.8)$ \\
\hline
\end{tabular}

\section{Gender}

A $t$ test was conducted to check for any differences between female and male results for each of the psychosocial variables. Of the 116 participants who provided data on their gender identity, 161 identified as Female, 53 as Male, and 2 chose not to specify their identity. This test showed that there were significant differences amongst female and male scores for both public self-monitoring $(t(212)=2.80, p<.01)$ and online bonding capital $(t(212)=2.50, p$ $=.01$ ). 
Table 2. Pearson Correlation Matrix of Assessed Variables.

\begin{tabular}{|c|c|c|c|c|c|c|c|c|}
\hline & SMEQ & FoMOs & SMS-R & PNSS & PSCS & SC Bonding & SC Bridging & Age \\
\hline SMEQ & & $.33^{* *}$ & .08 & -.04 & .10 & $.18^{* *}$ & $.21^{* *}$ & .12 \\
\hline FoMOs & & & $.20^{* *}$ & $-.18^{* *}$ & $.31^{* *}$ & $.17^{*}$ & $.37^{* *}$ & .05 \\
\hline SMS-R & & & & -.01 & $.19^{* *}$ & $.16^{*}$ & $.23^{* *}$ & $.14^{*}$ \\
\hline PNSS & & & & & $-.30^{* *}$ & .03 & -.04 & .02 \\
\hline PSCS & & & & & & .01 & $.14^{*}$ & .11 \\
\hline SC Bonding & & & & & & & $.51^{* *}$ & .03 \\
\hline SC Bridging & & & & & & & & .04 \\
\hline
\end{tabular}

Note. ${ }^{*} p<.05,{ }^{*} p<.01$.

\section{Ethnicity}

The majority of participants identified as European/Caucasian (57.3\%). This was followed by Asian (23.9\%), Pacific Islander (7.4\%), Māori (5.6\%), Middle Eastern (3.7\%), and African participants (1.4\%). A one-way ANOVA was used along with a series of Tukey post-hoc tests to assess whether there were any differences in the mean responses to each of the primary variables across ethnic groups. Discrepancies were identified between ethnic group means in responses to the $\operatorname{SMEQ}(F(5,210)=2.85, p=.02)$, with a significant difference found between European/Caucasian participants and Asian participants $(p=.02)$. A significant difference between group means was also identified in responses to the FoMOs $(F(5,210)=2.43, p=.04)$, with the greatest intergroup difference found between Māori participants $(M=1.83, S D=0.15)$ and Middle Eastern participants $(M=2.56, S D=0.27)$, although this difference in means was not found to be statistically significant $(p=.13)$.

\section{Age}

$73 \%$ of participants were aged between nineteen and 23 , with the youngest participant aged eighteen and the oldest aged 49. Age was measured as a continuous variable. These demographic data were therefore regressed onto each of the primary variables. A negative correlation was identified between age and public self-monitoring ( $\beta=-.14, p=.03$ ) despite more than $70 \%$ of participants being aged 22 or younger. This finding is consistent with a general perception of social maturity developing alongside age, with older individuals arguably being less likely to feel the need to monitor and adapt their social behaviour.

Inclusion of gender, ethnicity, and age as covariates had no impact on any subsequent analyses, and therefore these demographic variables will not be discussed with regard to the mediation models below.

\section{Mediation Analyses}

Upon completion of the preliminary analysis, data collected from the various psychosocial measures were used to conduct a simple mediation analysis using ordinary least squares path analysis (Hayes, 2018). Indirect effects were evaluated using 95\% percentile bootstrap confidence intervals based on 10,000 bootstrap samples. In some cases, a plot of the standardized predicted and residual values indicated mild heteroscedasticity, and therefore analyses were repeated using HC3 (Davidson-MacKinnon) and HC4 (Cribari-Neto) heteroscedasticity-consistent covariance estimators (Hayes \& Cai, 2007). These alternatives had no impact on the outcomes, hence the standard inferential method is reported below. Possible alternative models of the assessed variables were checked as part of our analysis. Of the 26 potential models, our ordering of the variables was the only one which resulted in significant and conceptually interpretable indirect relationships for all five predictors, and thus provides the most parsimonious model. All reported coefficients are completely standardized ( $\beta$ ).

\section{Public Self-Monitoring}

Public self-monitoring was indirectly related to SNS engagement through its relationship with FoMO. As displayed in Figure 1, higher public-self monitoring was associated with greater FoMO $(a=.20, p<.01)$, and greater FoMO 
was subsequently associated with higher SNS engagement $(b=.33, p<.001)$. The confidence interval indicated that the indirect effect $(a b=.07)$ was entirely above zero $(.02$ to .12$)$. There was no evidence that public selfmonitoring influenced SNS engagement independent of its effect on FoMO $\left(c^{\prime}=.02, p=.74\right)$.

Figure 1. Public Self-Monitoring Path Analysis.

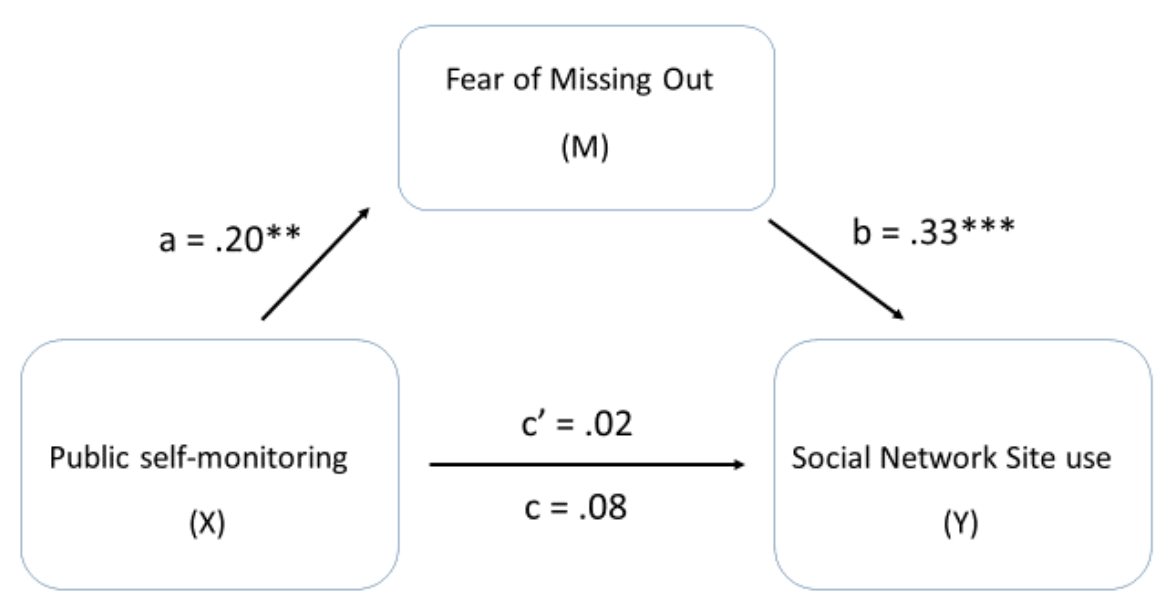

Note. Significant positive indirect effect was found between public self-monitoring and SNS use. No total or direct effect was found $(* * p<.01, * * * p<.001)$.

\section{Psychological Need Satisfaction}

Psychological need satisfaction was indirectly related to SNS engagement through its relationship with FoMO. As displayed in Figure 2, lower psychological need satisfaction was associated with greater FoMO $(a=-.18, p<.01)$, and greater FoMO was subsequently associated with higher SNS engagement $(b=.34, p<.001)$. The confidence interval indicated that the indirect effect $(a b=-.06)$ was entirely below zero $(-.12$ to -.02$)$. There was no evidence that psychological need satisfaction influenced SNS engagement independent of its effect on FoMO $\left(c^{\prime}=.02, p=\right.$ $.80)$.

Figure 2. Psychological Need Satisfaction Path Analysis.

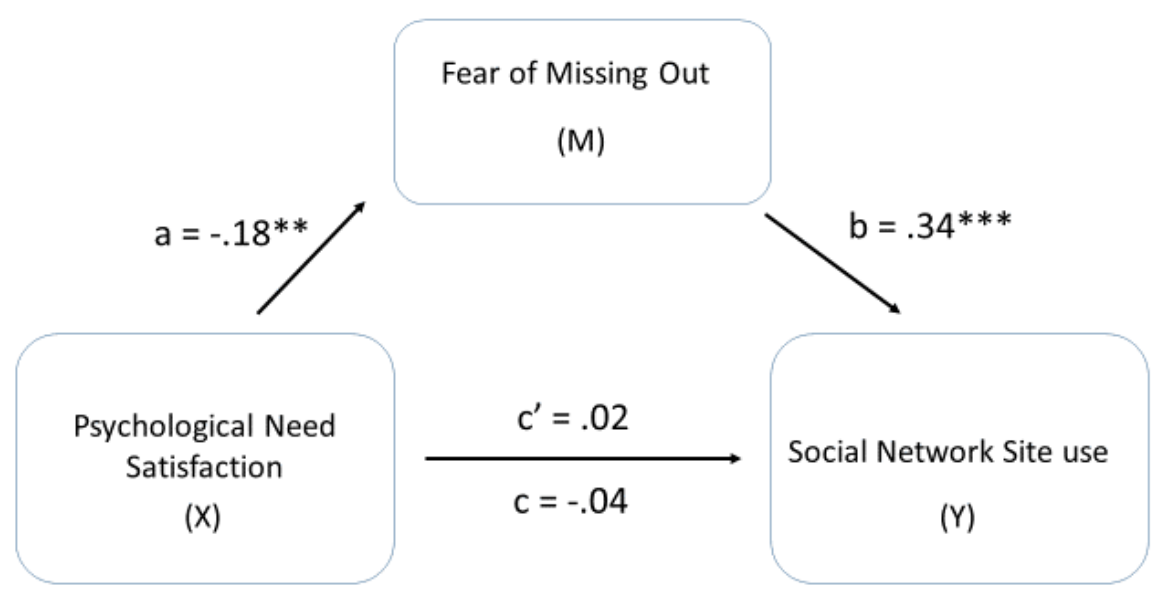

Note. Significant negative indirect effect was found between psychological need satisfaction and SNS use. No total or direct effect was found $(* * p<.01, * * * p<.001)$. 


\section{Public Self-Consciousness}

Public self-consciousness was indirectly related to SNS engagement through its relationship with FoMO. As displayed in Figure 3, greater public self-consciousness was associated with greater FoMO $(a=.31, p<.001)$, and greater FoMO was subsequently associated with higher SNS engagement $(b=.33, p<.001)$. The confidence interval indicated that the indirect effect $(a b=.10)$ was entirely above zero $(.05$ to .16$)$. There was no evidence that public self-consciousness influenced SNS engagement independent of its effect on FoMO $\left(c^{\prime}=.01, p=.94\right)$.

Figure 3. Public Self-Consciousness Path Analysis.

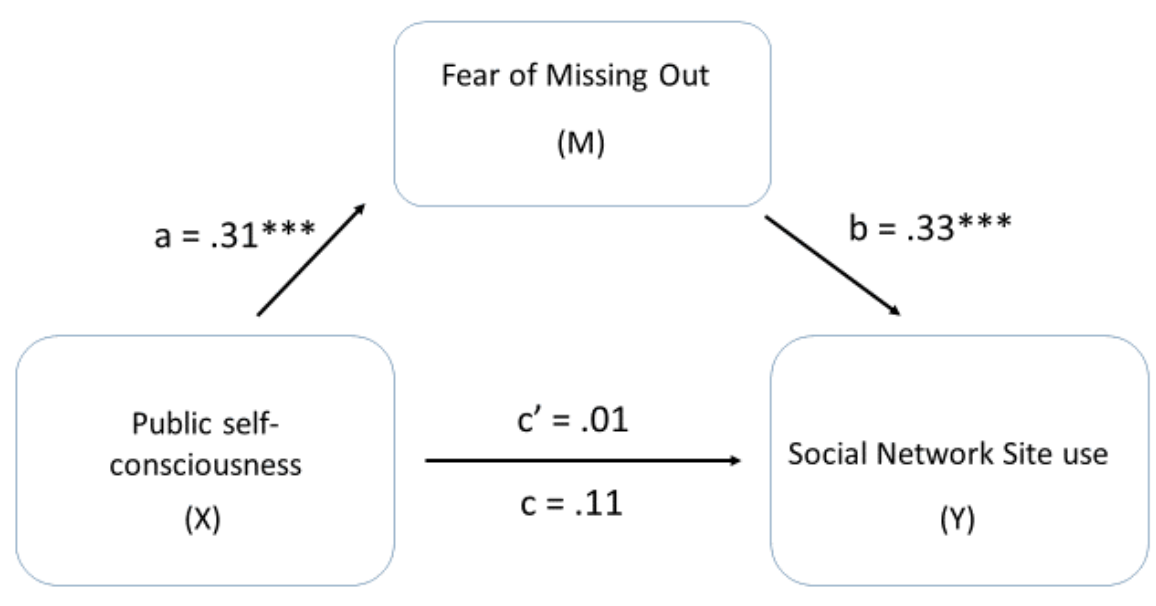

Note. Significant positive indirect effect was found between public self-consciousness and SNS use. No total or direct effect was found $(* * * p<.001)$.

\section{Bonding Social Capital}

Bonding social capital was indirectly related to SNS engagement through its relationship with FoMO. As displayed in Figure 4, more bonding social capital was associated with greater FoMO $(a=.17, p<.01)$, and greater FoMO was subsequently associated with higher SNS engagement $(b=.31, p<.001)$. The confidence interval indicated that the indirect effect $(a b=.05)$ was entirely above zero $(.01$ to .10$)$. Moreover, bonding social capital was positively related to SNS engagement even after accounting for the indirect effect via FoMO $\left(c^{\prime}=.13, p=.04\right)$.

Figure 4. Bonding Social Capital Path Analysis.

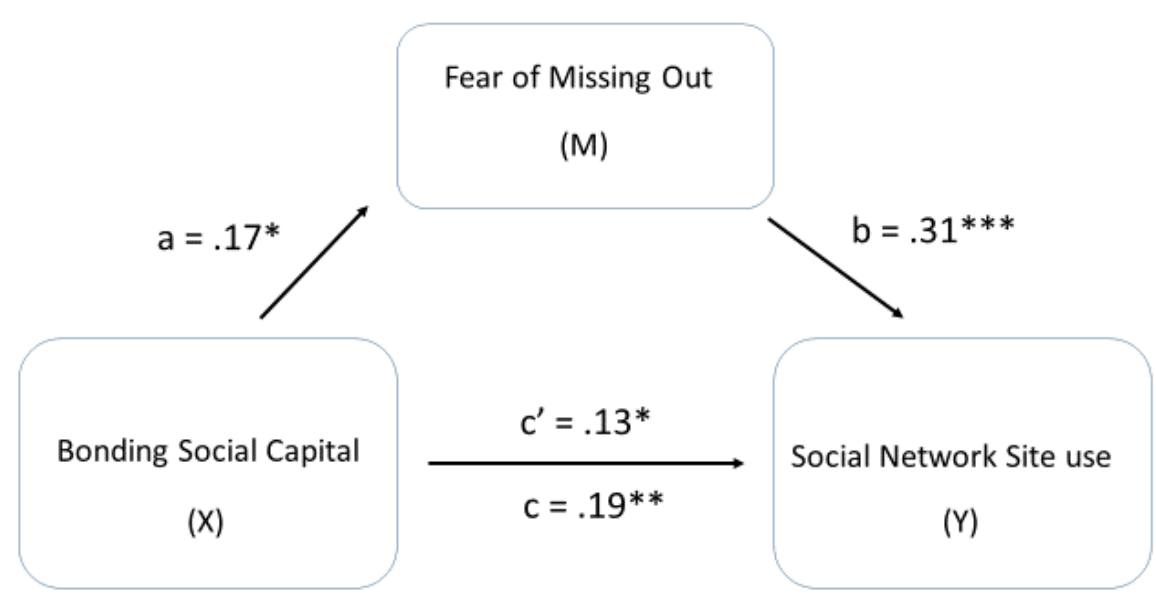

Note. Significant positive indirect effect was found between bonding social capital and SNS use, with significant positive total and significant positive direct effect $\left({ }^{*} p<.05,{ }^{* *} p<.01,{ }^{* * *} p<.001\right)$. 


\section{Bridging Social Capital}

Bridging social capital was indirectly related to SNS engagement through its relationship with FoMO. As displayed in Figure 5, more bridging social capital was associated with greater FoMO $(a=.37, p<.001)$, and greater FoMO was subsequently associated with higher SNS engagement $(b=.29, p<.001)$. The confidence interval indicated that the indirect effect $(a b=.11)$ was entirely above zero $(.06$ to .17$)$. There was no evidence that bridging social capital influenced SNS engagement independent of its effect on FoMO $\left(c^{\prime}=.11, p=.12\right)$.

Figure 5. Bridging Social Capital Path Analysis.

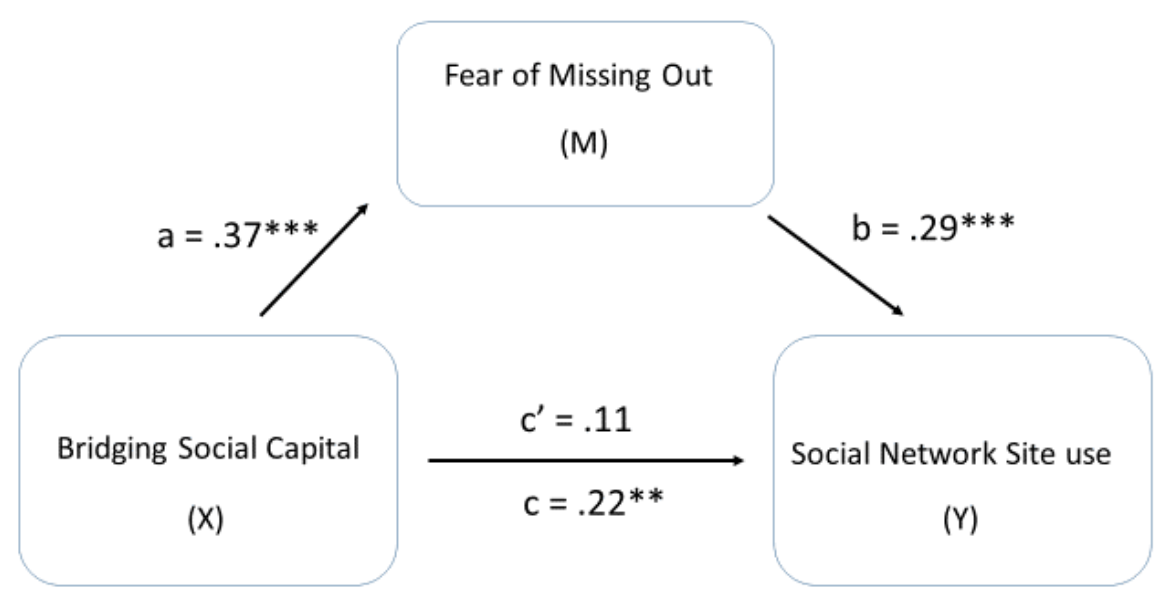

Note. Significant positive indirect effect was found between bridging social capital and SNS use, with significant positive total. No significant positive direct effect was found $(* * p<.01, * * * p<.001)$.

\section{Discussion}

The relationship between each of the assessed psychosocial variables and frequency of SNS engagement was found to be mediated by FoMO. Individuals with higher rates of online social capital, public self-consciousness, and public self-monitoring, were more likely to experience FoMO, and as a result, more likely to report higher rates of SNS engagement. Such relationships between these variables do not appear to have been identified in any prior literature and may therefore prove an interesting avenue for further exploration. Individuals with lower rates of psychological need satisfaction were more likely to have higher rates of SNS engagement by way of FoMO, a finding which is consistent with previous work in this field. These results support our initial hypotheses that FoMO is a key mechanism in explaining the close association between social connectivity and rates of SNS engagement.

\section{Psychological Need Satisfaction}

Participants with lower levels of psychological need satisfaction in their day-to-day lives were found to be more likely to experience FoMO, and as a result were more likely to report higher rates of SNS engagement than their high PNSS counterparts. These findings are consistent with those of Przybylski et al. (2013) and imply that SNS users feel they can retreat to the online realm to satisfy their need for a sense of autonomy, competence and relatedness in their daily lives. These findings further illustrate how closely intertwined online and offline social identities have become in the digital age and have implications for strategies aimed at reducing excessive SNS use. By improving SNS users' capacity to fulfil their psychological needs in an offline context, these findings suggest that users may be less susceptible to problematic SNS engagement as result of FoMO. Despite this, it is also important to note that these findings fall short of conclusively demonstrating that online psychological need satisfaction is equivalent to offline need satisfaction in terms of a user's psychosocial wellbeing. 


\section{Public Self-Consciousness and Public Self-Monitoring}

A central feature of almost all social media sites is the construction and maintenance of a publically visible identity or profile. Although the visibility and customisable nature of these profiles varies across platforms, these features have quickly become an integral aspect of social identity formation in the digital age (Greenhow \& Robelia, 2009). In the context of rapidly evolving online social landscapes, many users are acutely aware of how their online identities might be construed by others (Cingel \& Krcmar, 2014), and managing and maintaining these identities is a key aspect of the social media experience. The allure of the curatorial nature of online identities was reflected in our findings. Both public self-consciousness and self-monitoring were found to be associated with SNS engagement by way of increased propensity to experience FoMO. Individuals who are more conscious of themselves as an object of social attention, and more likely to engage in self-monitoring behaviours, may be more prone to FoMO due to their desire to cultivate a social identity which is responsive to current social information. Social media platforms represent a rich source of such social information, and the easily accessible and everpresent nature of SNS provides a potential remedy to FoMO which is often only a click away.

\section{Social Capital}

FoMO was also found to mediate the relationship between bridging and bonding online social capital and SNS engagement. The relationships between bridging and bonding online capital, FoMO and SNS found in this study have congruence with both an academic (Hampton et al., 2011), and an anecdotal understanding of how people use SNS. SNS platforms such as Facebook enable users to collect and collate very large lists/networks of 'friends', often numbering in the hundreds and even thousands (Dunbar, 2016). This is possibly due to the ease with which people are able to add new members to their online networks. This results in a high prevalence of extensive online social networks which often far exceed the amount of close social relationships one individual can realistically maintain (Dunbar, 1992). In terms of an individual's need for emotionally intimate social relationships, having online social networks which number in the hundreds might be considered socially excessive, with a significant portion of those networks likely consisting of relatively weak social ties. This is supported in recent research which found that despite the increased communication and connection afforded by SNSs, there is still a limit on the number of functional social relationships one individual can maintain (Dunbar, 2016). This implies that a significant portion of the perceived social capital accumulated within SNS platforms can be considered as bridging social capital. Greater networks with less inherent social support and stability may result in increased susceptibility to anxiety regarding missed opportunities for social gratification. This is particularly relevant with regards to SNS engagement, in which social information is most often shared in a public forum. Large networks of loose associations in these social arenas potentially mean that there is more social significance placed on publicly visible displays of closeness and connectivity, and therefore even more significance placed on missed opportunities and experiences.

This perspective was supported by our results in which the extent that FoMO mediated the relationship between bridging capital and SNS engagement was significantly greater than in the case of bonding capital. This indicates that users with larger networks of loose affiliations and casual acquaintances may be more prone to increased SNS engagement by way of increased FoMO. One reason for this may be the differences in perceived social gratification derived from bridging and bonding online social capital. While a lot of bonding capital equates to a lot of emotionally close relationships, more bridging social capital means a greater amount of potentially tenuous or superficial social connections (Putnam, 2000). These superficial connections are important to an individual to the extent that they can be capitalised on for social gain. An SNS user with high rates of bridging social capital online may be more likely to see posts, videos or photos whilst using SNS which make them aware of a missed opportunity to strengthen or capitalise on their bridging relationships, thus stimulating feelings of FoMO.

Our findings suggest that as rates of social capital fluctuate, so too do rates of SNS engagement. These findings at first appear to stand in contradiction with a recent study of social capital and SNS use, and provide an example of the value of diverse methodological approaches to conducting SNS related research. Yoo and Jeong (2017) conducted a longitudinal, two-wave, study which found that both high and low social capital users used SNS just as frequently as one another. As a result of their findings, they argued that there was no correlation between user's social capital and the amount of time spent actively using SNS. There are however several key differences between Yoo and Jeong's study and the present study. The most significant difference is that Yoo and Jeong (2017) 
appear to have categorised all participants into either a high or low social capital group, before assessing how rates of SNS engagement relates to this variable. This dichotomous assessment of social capital means that their findings may not reflect the full range of variability within the social capital variable, and therefore only provide limited insight into the relationship between social capital and SNS use. In the present study's analysis, the full range of social capital scores for all users were regressed onto SNS engagement scores simultaneously. This meant that the correlation found between these two variables was assessed with greater statistical power than in Yoo and Jeong's study, and therefore we might have been capable of detecting effects that were not apparent in previous research.

Another key difference between the findings of the present study and Yoo and Jeong (2017), can be seen in the methods used to assess rates of SNS engagement. The present study utilised Przybylski et al.'s (2013) social media engagement questionnaire as a means of assessing levels of SNS engagement. This questionnaire consisted of multiple questions which sought to assess the degree to which participants engaged with SNS at different times of the day over the last week. Meanwhile, Yoo and Jeong's (2017) study measured SNS engagement according to participant responses to one open-ended question regarding how much time they spent actively using SNS per day. The differences in the method with which SNS engagement was assessed in these two studies is an important factor to consider in the comparison of their respective findings.

\section{Methodological Discrepancies}

Our assessment of two of the independent variables included in this study was inconsistent with prior social psychological research. The applications of both the PSCS and the PNS scale were simplified in this study. Rather than answering using scales, participants instead responded to the questions in these tools with simply True or False. The internal reliability of the simplified versions of these scales was found to be consistent with the original incarnations of the tools. This indicated that the scales were still internally reliable as measures of their respective psychosocial constructs, only they were not measuring these constructs with the same depth as the original scales. Despite this methodological discrepancy, our findings still proved significant. This reinforces the work of similar studies in this area which have established robust correlations between PNS and SNS engagement (Masur et al., 2014; Przybylski et al., 2013), as well as between PNS and online activities in general (Przybylski et al., 2009). Although we are not aware of any previous studies linking public self-consciousness with experiences of FoMO, the fact that a significant association was found between these variables and SNS engagement, despite using a simplified measure of public self-consciousness, leaves room for further investigation into the nature of such relationships.

\section{Limitations}

The non-random sample used in this study may be interpreted as representative of New Zealand tertiary students who are SNS users, a demographic which holds significant relevance to discussions on the impact of social media. However, the limited generalisability of findings from a relatively small and specific sample is also important to note, a limitation which reflects the budgetary constraints of our research team. Although our hypotheses were supported by our findings, confidence in the generalisability of these results would be increased by replications using other more diverse samples.

A key limitation of both the present study and other similar studies within the field (Alt, 2015; Przybylski et al., 2013; Ross et al., 2009; Yoo \& Jeong, 2017), is the limited insight provided into the extent to which deficits in aspects of psychosocial wellbeing might be considered as either motivations or consequences of high rates of SNS engagement. While variables such as FoMO and SNS engagement have been consistently shown to be interrelated, there still appears to be a lack of clarity on whether individuals use SNS because they are prone to fear missing out, or whether individuals are more likely to fear missing out because of their SNS use. Although appropriate steps were taken to confirm the directionality of the relationships within our statistical model, ultimately this was a correlational study and more experimental approaches to future work in this field may prove fruitful. Improving clarity on the directionality of relationships between variables associated with SNS use remains an important frontier for social media research. 
Another important limitation when considering the implications of the present study is the aforementioned inconsistencies in two of the psychosocial measures in relation to previous research within the field. By modifying the participant response options to the items in the PNSS and the PSCS, the psychometric depth with which these variables were assessed was partially impacted. Although there is no reason to believe that the data collected from these subscales was completely compromised by this modification, the extent to which this data can be contrasted with the findings of studies using the original unaltered subscales is important to take into account.

As with many similar studies within this field, the reliability of data collected via self-report questionnaire is a key limitation of the present study. Precautions such as assuring the anonymity of data were taken to reduce the social desirability bias associated with responses to the self-report subscales. However, it has to be assumed that some degree of social desirability bias is still present within the data, as is true with many self-report studies of psychosocial phenomena. This bias might have been reduced by including some form of a social desirability response scale as an additional component in the primary study (Van de Mortel, 2008).

\section{Conclusions}

There is still much to be accomplished in terms of our quantitative understanding of the nature of SNS use. The four psychosocial factors assessed in this study represent a small sample of a wide array of interrelating factors which may influence SNS engagement. The same can be said for FoMO, which is only one example of a host of psychological mechanisms which contribute to SNS engagement. Ideally, the quantitative findings presented here will continue to be built upon and developed further in ongoing attempts to understand the social psychological motivations and impacts of SNS use.

\section{References}

Al-Menayes, J. (2016). The Fear of Missing Out Scale: Validation of the Arabic version and correlation with social media addiction. International Journal of Applied Psychology, 6(2), 41-46.

http://article.sapub.org/10.5923.j.ijap.20160602.04.html

Alt, D. (2015). College students' academic motivation, media engagement and fear of missing out. Computers in Human Behavior, 49, 111-119. https://doi.org/10.1016/j.chb.2015.02.057

Appel, M., Krisch, N., Stein, J.-P., \& Weber, S. (2019). Smartphone zombies! Pedestrians' distracted walking as a function of their fear of missing out. Journal of Environmental Psychology, 63, 130-133.

https://doi.org/10.1016/j.jenvp.2019.04.003

Barker, E. (2016, June 7). This is the best way to overcome fear of missing out. Time Magazine. http://time.com/4358140/overcome-fomo/

Baumeister, R. F. (1984). Choking under pressure: Self-consciousness and paradoxical effects of incentives on skillful performance. Journal of Personality and Social Psychology, 46(3), 610-620. https://doi.org/10.1037/00223514.46.3.610

BBC. (2017, March 1). FOMO: How the Fear of Missing Out drives social media 'addiction'. BBC News.

http://www.bbc.com/news/technology-39129228

Beyens, I., Frison, E., \& Eggermont, S. (2016). "I don't want to miss a thing": Adolescents' fear of missing out and its relationship to adolescents' social needs, Facebook use, and Facebook related stress. Computers in Human Behavior, 64, 1-8. https://doi.org/10.1016/j.chb.2016.05.083

Briggs, S. R., Cheek, J. M., \& Buss, A. H. (1980). An analysis of the Self-Monitoring Scale. Journal of Personality and Social Psychology, 38(4), 679-686. https://doi.org/10.1037/0022-3514.38.4.679

Brown, J. D. (1998). The self. Routledge. 
Cata, T., Patel, P. S., \& Sakaguchi, T. (2013). QR code: A new opportunity for effective mobile marketing. Journal of Mobile Technologies, Knowledge and Society, 2013, Article 748267.

https://ibimapublishing.com/articles/JMTKS/2013/748267/

Chai, H.-Y., Niu, G.-F., Lian, S.-L., Chu, X.-W., Liu, S., \& Sun, X.-J. (2019). Why social network site use fails to promote well-being? The roles of social overload and fear of missing out. Computers in Human Behavior, 100, 85-92. https://doi.org/10.1016/j.chb.2019.05.005

Chen, X., Stanton, B., Gong, J., Fang, X., \& Li, X. (2009). Personal Social Capital Scale: An instrument for health and behavioral research. Health Education Research, 24(2), 306-317. https://doi.org/10.1093/her/cyn020

Chotpitayasunondh, V., \& Douglas, K. M. (2016). How "phubbing" becomes the norm: The antecedents and consequences of snubbing via smartphone. Computers in Human Behavior, 63, 9-18.

https://doi.org/10.1016/j.chb.2016.05.018

Chua, T. H. H., \& Chang, L. (2016). Follow me and like my beautiful selfies: Singapore teenage girls' engagement in self-presentation and peer comparison on social media. Computers in Human Behavior, 55(Part A), 190-197. https://doi.org/10.1016/j.chb.2015.09.011

Cingel, D. P., \& Krcmar, M. (2014). Understanding the experience of imaginary audience in a social media environment: Implications for adolescent development. Journal of Media Psychology: Theories, Methods, and Applications, 26(4), 155-160. https://doi.org/10.1027/1864-1105/a000124

Dabner, N. (2012). 'Breaking Ground' in the use of social media: A case study of a university earthquake response to inform educational design with Facebook. The Internet and Higher Education, 15(1), 69-78.

https://doi.org/10.1016/j.iheduc.2011.06.001

David, M. E., \& Roberts, J. A. (2017). Phubbed and alone: Phone snubbing, social exclusion, and attachment to social media. Journal of the Association for Consumer Research, 2(2), 155-163. https://doi.org/10.1086/690940

Deci, E. L., \& Ryan, R. M. (1985). Intrinsic motivation and self-determination in human behavior. Plenum Press.

Dhir, A., Yossatorn, Y., Kaur, P., \& Chen, S. (2018). Online social media fatigue and psychological wellbeing-A study of compulsive use, fear of missing out, fatigue, anxiety and depression. International Journal of Information Management, 40, 141-152. https://doi.org/10.1016/j.jinfomgt.2018.01.012

Dou, X., \& Li, H. (2008). Creative use of QR codes in consumer communication. International Journal of Mobile Marketing, 3(2), 61-67.

Dunbar, R. I. M. (1992). Neocortex size as a constraint on group size in primates. Journal of Human Evolution, 22(6), 469-493. https://doi.org/10.1016/0047-2484(92)90081-J

Dunbar, R. I. M. (2016). Do online social media cut through the constraints that limit the size of offline social networks? Royal Society Open Science, 3(1), Article 150292. https://doi.org/10.1098/rsos.150292

Elhai, J. D., Yang, H., Fang, J., Bai, X., \& Hall, B. J. (2020). Depression and anxiety symptoms are related to problematic smartphone use severity in Chinese young adults: Fear of missing out as a mediator. Addictive Behaviors, 101, Article 105962. https://doi.org/10.1016/j.addbeh.2019.04.020

Ellison, N. B., Steinfield, C., \& Lampe, C. (2007). The benefits of Facebook "friends:" Social capital and college students' use of online social network sites. Journal of Computer-Mediated Communication, 12(4), 1143-1168. https://doi.org/10.1111/j.1083-6101.2007.00367.x 
Ellison, N. B., Steinfield, C., \& Lampe, C. (2011). Connection strategies: Social capital implications of Facebookenabled communication practices. New Media \& Society, 13(6), 873-892.

https://doi.org/10.1177/1461444810385389

Ellison, N. B., Vitak, J., Gray, R., \& Lampe, C. (2014). Cultivating social resources on social network sites: Facebook relationship maintenance behaviors and their role in social capital processes. Journal of Computer-Mediated Communication, 19(4), 855-870. https://doi.org/10.1111/jcc4.12078

Fake, C. (2011, March 15). FOMO and social media. Caterina.net. https://caterina.net/2011/03/15/fomo-andsocial-media/

Fenigstein, A., Scheier, M. F., \& Buss, A. H. (1975). Public and private self-consciousness: Assessment and theory. Journal of Consulting and Clinical Psychology, 43(4), 522-527. https://doi.org/10.1037/h0076760

Finkel, E. J., \& Baumeister, R. F. (2019). Social psychology: Crisis and renaissance. In E. J. Finkel \& R. F. Baumeister (Eds.), Advanced social psychology: The state of the science (2nd ed., pp. 1-8). Oxford University Press.

Fritz, M. S., \& MacKinnon, D. P. (2007). Required sample size to detect the mediated effect. Psychological Science, 18(3), 233-239. https://doi.org/10.1111/j.1467-9280.2007.01882.x

Frost, R. L., \& Rickwood, D. J. (2017). A systematic review of the mental health outcomes associated with Facebook use. Computers in Human Behavior, 76, 576-600. https://doi.org/10.1016/j.chb.2017.08.001

Gökler, M. E., Aydın, R., Ünal, E., \& Metintaş, S. (2016). Sosyal Ortamlarda Gelişmeleri Kaçırma Korkusu Ölçeğinin Türkçe sürümünün geçerlilik ve güvenilirliğinin değerlendirilmesi [Determining validity and reliability of Turkish version of Fear of Missing out Scale]. Anatolian Journal of Psychiatry, 17, 53-59.

http://dx.doi.org/10.5455/apd.195843

Green, M. C., Kaufman, G., Flanagan, M., \& Fitzgerald, K. (2017). Self-esteem and public self-consciousness moderate the emotional impact of expressive writing about experiences with bias. Personality and Individual Differences, 116, 212-215. https://doi.org/10.1016/j.paid.2017.04.057

Greenhow, C., \& Robelia, B. (2009). Informal learning and identity formation in online social networks. Learning, Media and Technology, 34(2), 119-140. https://doi.org/10.1080/17439880902923580

Hampton, K. N., Sessions, L. F., \& Her, E. J. (2011). Core networks, social isolation, and new media: How Internet and mobile phone use is related to network size and diversity. Information, Communication \& Society, 14(1), 130155. https://doi.org/10.1080/1369118X.2010.513417

Hawi, N. S., \& Samaha, M. (2017). The relations among social media addiction, self-esteem, and life satisfaction in university students. Social Science Computer Review, 35(5), 576-586. https://doi.org/10.1177/0894439316660340

Hayes, A. F. (2018). Introduction to mediation, moderation, and conditional process analysis (2nd ed.). Guilford Press.

Hayes, A. F. \& Cai, L. (2007). Using heteroskedasticity-consistent standard error estimators in OLS regression: An introduction and software implementation. Behavior Research Methods, 39(4), 709-722.

https://doi.org/10.3758/BF03192961

He, Q., Turel, O., \& Bechara, A. (2017). Brain anatomy alterations associated with Social Networking Site (SNS) addiction. Scientific Reports, 7, Article 45064. https://doi.org/10.1038/srep45064

Hetz, P. R., Dawson, C. L., \& Cullen, T. A. (2015). Social media use and the fear of missing out (FoMO) while studying abroad. Journal of Research on Technology in Education, 47(4), 259-272.

https://doi.org/10.1080/15391523.2015.1080585 
Holmgren, H. G., \& Coyne, S. M. (2017). Can't stop scrolling!: Pathological use of social networking sites in emerging adulthood. Addiction Research \& Theory, 25(5), 375-382.

https://doi.org/10.1080/16066359.2017.1294164

Jelenchick, L. A., Eickhoff, J. C., \& Moreno, M. A. (2013). “Facebook depression?" Social networking site use and depression in older adolescents. Journal of Adolescent Health, 52(1), 128-130.

https://doi.org/10.1016/j.jadohealth.2012.05.008

La Guardia, J. G., Ryan, R. M., Couchman, C. E., \& Deci, E. L. (2000). Within-person variation in security of attachment: A self-determination theory perspective on attachment, need fulfillment, and well-being. Journal of Personality and Social Psychology, 79(3), 367-384. https://doi.org/10.1037/0022-3514.79.3.367

Lee, J.-E. R., Moore, D. C., Park, E.-A., \& Park, S. G. (2012). Who wants to be "friend-rich"? Social compensatory friending on Facebook and the moderating role of public self-consciousness. Computers in Human Behavior, 28(3), 1036-1043. https://doi.org/10.1016/j.chb.2012.01.006

Lennox, R. D., \& Wolfe, R. N. (1984). Revision of the Self-Monitoring Scale. Journal of Personality and Social Psychology, 46(6), 1349-1364. https://doi.org/10.1037/0022-3514.46.6.1349

Livingstone, S. (2008). Taking risky opportunities in youthful content creation: Teenagers' use of social networking sites for intimacy, privacy and self-expression. New Media \& Society, 10(3), 393-411. https://doi.org/10.1177/1461444808089415

Lowery, S. E., Robinson Kurpius, S. E., Befort, C., Hull Blanks, E., Sollenberger, S., Foley Nicpon, M., \& Huser, L. (2005). Body image, self-esteem, and health-related behaviors among male and female first year college students. Journal of College Student Development, 46(6), 612-623. https://doi.org/10.1353/csd.2005.0062

Lundh, L.-G., \& Öst, L.-G. (2001). Attentional bias, self-consciousness and perfectionism in social phobia before and after cognitive-behaviour therapy. Scandinavian Journal of Behaviour Therapy, 30(1), 4-16.

https://doi.org/10.1080/02845710117841

Masur, P. K., Reinecke, L., Ziegele, M., \& Quiring, O. (2014). The interplay of intrinsic need satisfaction and Facebook specific motives in explaining addictive behavior on Facebook. Computers in Human Behavior, 39, 376386. https://doi.org/10.1016/j.chb.2014.05.047

Miller, L. C., \& Cox, C. L. (1982). For appearances' sake: Public self-consciousness and makeup use. Personality and Social Psychology Bulletin, 8(4), 748-751. https://doi.org/10.1177/0146167282084023

Milner, R. M. (2016). The world made meme: Public conversations and participatory media. MIT Press.

Oberst, U., Wegmann, E., Stodt, B., Brand, M., \& Chamarro, A. (2017). Negative consequences from heavy social networking in adolescents: The mediating role of fear of missing out. Journal of Adolescence, 55, 51-60.

https://doi.org/10.1016/j.adolescence.2016.12.008

Onyx, J., \& Bullen, P. (2000). Measuring social capital in five communities. The Journal of Applied Behavioral Science, 36(1), 23-42. https://doi.org/10.1177/0021886300361002

Perrone, M. A. (2016). \#FoMO: Establishing validity of the Fear of Missing Out Scale with an adolescent population [Doctoral dissertation, Alfred University]. Alfred University Research \& Archives.

http://hdl.handle.net/10829/7399

Przybylski, A. K., Murayama, K., DeHaan, C. R., \& Gladwell, V. (2013). Motivational, emotional, and behavioral correlates of fear of missing out. Computers in Human Behavior, 29(4), 1841-1848.

https://doi.org/10.1016/j.chb.2013.02.014 
Przybylski, A. K., Rigby, C. S., \& Ryan, R. M. (2010). A motivational model of video game engagement. Review of General Psychology, 14(2), 154-166. https://doi.org/10.1037/a0019440

Przybylski, A. K., Weinstein, N., Ryan, R. M., \& Rigby, C. S. (2009). Having to versus wanting to play: Background and consequences of harmonious versus obsessive engagement in video games. CyberPsychology \& Behavior, 12(5), 485-492. https://doi.org/10.1089/cpb.2009.0083

Putnam, R. D. (2000). Bowling alone: America's declining social capital. Simon \& Schuster.

Qutteina, Y., Nasrallah, C., Kimmel, L., \& Khaled, S. M. (2019). Relationship between social media use and disordered eating behavior among female university students in Qatar. Journal of Health and Social Sciences, 4(1), 59-72. https://journalhss.com/wp-content/uploads/jhss41_59-72.pdf

Rahmadani, V. G., Schaufeli, W. B., Ivanova, T. Y., \& Osin, E. N. (2019). Basic psychological need satisfaction mediates the relationship between engaging leadership and work engagement: A cross-national study. Human Resource Development Quarterly, 30(4), 453-471. https://doi.org/10.1002/hrdq.21366

Reer, F., Tang, W. Y., \& Quandt, T. (2019). Psychosocial well-being and social media engagement: The mediating roles of social comparison orientation and fear of missing out. New Media \& Society, 21(7), 1486-1505.

https://doi.org/10.1177/1461444818823719

Robson, T. (2018). Fear of Missing Out - An essential correlate of social networking site addiction. American Journal of Medical Research, 5(1), 85-90. https://doi.org/10.22381/AJMR5120188

Ross, C., Orr, E. S., Sisic, M., Arseneault, J. M., Simmering, M. G., \& Orr, R. R. (2009). Personality and motivations associated with Facebook use. Computers in Human Behavior, 25(2), 578-586.

https://doi.org/10.1016/j.chb.2008.12.024

Seidman, G. (2013). Self-presentation and belonging on Facebook: How personality influences social media use and motivations. Personality and Individual Differences, 54(3), 402-407. https://doi.org/10.1016/j.paid.2012.10.009

Sheldon, K. M., Abad, N., \& Hinsch, C. (2011). A two-process view of Facebook use and relatedness needsatisfaction: Disconnection drives use, and connection rewards it. Journal of Personality and Social Psychology, 100(4), 766-775. https://doi.org/10.1037/a0022407

Sherlock, M., \& Wagstaff, D. L. (2018). Exploring the relationship between frequency of Instagram use, exposure to idealized images, and psychological well-being in women. Psychology of Popular Media Culture, 8(4), 482-490. https://doi.org/10.1037/ppm0000182

Shim, M., Lee, M. J., \& Park, S. H. (2008). Photograph use on social network sites among South Korean college students: The role of public and private self-consciousness. CyberPsychology \& Behavior, 11(4), 489-493.

https://doi.org/10.1089/cpb.2007.0104

Shimoga, S. V., Erlyana, E., \& Rebello, V. (2019). Associations of social media use with physical activity and sleep adequacy among adolescents: Cross-sectional survey. Journal of Medical Internet Research, 21(6), Article e14290. https://doi.org/10.2196/14290

Snyder, M. (1974). Self-monitoring of expressive behavior. Journal of Personality and Social Psychology, 30(4), 526537. https://doi.org/10.1037/h0037039

Snyder, M., \& Gangestad, S. (1986). On the nature of self-monitoring: Matters of assessment, matters of validity. Journal of Personality and Social Psychology, 51(1), 125-139. https://doi.org/10.1037/0022-3514.51.1.125 
Spraggins, A. (2009). Problematic use of online social networking sites for college students: Prevalence, predictors, and association with well-being [Doctoral dissertation, University of Florida]. University of Florida Digital Collections. https://ufdc.ufl.edu/UFE0024085/00001

Steinfield, C., DiMicco, J. M., Ellison, N. B., \& Lampe, C. (2009). Bowling online: Social networking and social capital within the organization. In Proceedings of the fourth international conference on Communities and technologies (pp. 245-254). ACM. https://doi.org/10.1145/1556460.1556496

Tang, C. S.-K., \& Koh, Y. Y. W. (2017). Online social networking addiction among college students in Singapore: Comorbidity with behavioral addiction and affective disorder. Asian Journal of Psychiatry, 25, 175-178. https://doi.org/10.1016/j.ajp.2016.10.027

Tourangeau, R. (2018). The survey response process from a cognitive viewpoint. Quality Assurance in Education, 26(2), 169-181. https://doi.org/10.1108/QAE-06-2017-0034

Van de Mortel, T. F. (2008). Faking it: Social desirability response bias in self-report research. The Australian Journal of Advanced Nursing, 25(4), 40-48. https://www.ajan.com.au/archive/Vol25/Vol_25-4_vandeMortel.pdf

Wang, J., Wang, P., Yang, X., Zhang, G., Wang, X., Zhao, F., Zhao, M., \& Lei, L. (2019). Fear of missing out and procrastination as mediators between sensation seeking and adolescent smartphone addiction. International Journal of Mental Health and Addiction, 17(4), 1049-1062. https://doi.org/10.1007/s11469-019-00106-0

Waterloo, S. F., Baumgartner, S. E., Peter, J., \& Valkenburg, P. M. (2017). Norms of online expressions of emotion: Comparing Facebook, Twitter, Instagram, and WhatsApp. New Media \& Society, 20(5), 1813-1831.

https://doi.org/10.1177/1461444817707349

Wiederman, M. W. (2000). Women's body image self-consciousness during physical intimacy with a partner. Journal of Sex Research, 37(1), 60-68. https://doi.org/10.1080/00224490009552021

Williams, D. (2006). On and off the 'Net: Scales for social capital in an online era. Journal of Computer-Mediated Communication, 11(2), 593-628. https://doi.org/10.1111/j.1083-6101.2006.00029.x

Wilmot, M. P., DeYoung, C. G., Stillwell, D., \& Kosinski, M. (2016). Self-monitoring and the metatraits. Journal of Personality, 84(3), 335-347. https://doi.org/10.1111/jopy.12162

Wolniewicz, C. A., Rozgonjuk, D., \& Elhai, J. D. (2019). Boredom proneness and fear of missing out mediate relations between depression and anxiety with problematic smartphone use. Human Behavior and Emerging Technologies, 2(1), 61-70. https://doi.org/10.1002/hbe2.159

Wolniewicz, C. A., Tiamiyu, M. F., Weeks, J. W., \& Elhai, J. D. (2018). Problematic smartphone use and relations with negative affect, fear of missing out, and fear of negative and positive evaluation. Psychiatry Research, 262, 618-623. https://doi.org/10.1016/j.psychres.2017.09.058

Wortham, J. (2011, April 9). Feel like a wallflower? Maybe it's your Facebook wall. The New York Times. http://www.nytimes.com/2011/04/10/business/10ping.html

Xue, Y., Dong, Y., Luo, M., Mo, D., Dong, W., Zhang, Z., \& Liang, H. (2018). Investigating the impact of mobile SNS addiction on individual's self-rated health. Internet Research, 28(2), 278-292. https://doi.org/10.1108/IntR-05-20170198

Yoo, J. H., \& Jeong, E. J. (2017). Psychosocial effects of SNS use: A longitudinal study focused on the moderation effect of social capital. Computers in Human Behavior, 69, 108-119. https://doi.org/10.1016/j.chb.2016.12.011 
Correspondence to:

Ben Classen

Wellington

New Zealand

Email: bclassen77(at)gmail.com

Editorial record: First submission received on March 12, 2019. Revisions received on December 23, 2019 and April 22, 2020. Accepted for publication on April 22, 2020.

Editor in charge: Alexander Schouten

\section{About Authors}

Ben Classen, BHSC, MA, is a doctoral candidate who is currently based at Victoria University of Wellington, NZ. His research interests include the social psychological impacts of social media use, as well as the formation of social and moral norms in online environments.

Jay K. Wood, Ph.D. is a Senior Lecturer in Psychology in the School of Social Sciences and Public Policy at the Auckland University of Technology, New Zealand. His research explores social influence and the processes underlying social behaviour, as well as social and cognitive bases of the beliefs that we hold.

Patsi Davies, LL.B (Hons), Senior Fellow Higher Education Authority (UK) is a Lecturer in Health Promotion/Public Health in the Department of Public and Environmental Health at the Auckland University of Technology, New Zealand. Her research explores health, human rights, public policy, and law in the context of societies. 